\title{
Interactions of CAF1-NOT complex components from
}

\section{Trypanosoma brucei [version 1; peer review: 2 approved with}

\section{reservations]}

\author{
Chaitali Chakraborty ${ }^{1}$, Abeer Fadda1,2, Esteban Erben ${ }^{1,3}$, Smiths Lueong ${ }^{3,4}$, \\ Jörg Hoheisel ${ }^{3}$, Elisha Mugo ${ }^{1}$, Christine Clayton (iD1
}

${ }^{1}$ Division of Functional Genome Analysis, Deutsche Krebsforschungszentrum, Heidelberg, D69120, Germany

${ }^{2}$ Sidra Medical and Research Center, Doha, Qatar

${ }^{3}$ DKFZ-ZMBH Alliance, Zentrum für Moleckulare Biologie der Universität Heidelberg, Heidelberg, D69120, Germany

${ }^{4}$ Universitätsklinikum Essen, Essen, D45122, Germany

V1 First published: 09 Jun 2017, 6:858

https://doi.org/10.12688/f1000research.11750.1

Latest published: 09 Jun 2017, 6:858

https://doi.org/10.12688/f1000research.11750.1

\section{Abstract}

The CAF1-NOT complex of Trypanosoma brucei, like that of other eukaryotes, contains several NOT proteins (NOT1, NOT3, NOT3/5, NOT10, and NOT11), NOT9/CAF40, and the CAF1 deadenylase, which targets 3' poly(A) tails. Again like other eukaryotes, deadenylation is the first step in the degradation of most trypanosome mRNAs. In animal cells, destruction of unstable mRNAs is accelerated by proteins that bind the RNA in a sequence-specific fashion, and also recruit the CAF1-NOT complex. However, this has not yet been demonstrated for T. brucei. To find interaction partners for the trypanosome NOT complex, we did a genome-wide yeast two-hybrid screen, using a random shotgun protein fragment library, with the subunits CAF40, NOT2, NOT10 and NOT11 as baits. To assess interaction specificity, we compared the results with those from other trypanosome proteins, including the cyclin-F-box protein CFB1. The yeast 2-hybrid screen yielded four putatively interacting proteins for NOT2, eleven for NOT11, but only one for NOT9/CAF40. Both CFB1 and NOT10 had over a hundred potential interactions, indicating a lack of specificity. Nevertheless, a detected interaction between NOT10 and NOT11 is likely to be genuine. We also identified proteins that co-purify with affinity tagged NOT9/CAF40 by mass spectrometry. The co-purifying proteins did not include the 2-hybrid partner, but the results confirmed NOT9/CAF40 association with the CAF1-NOT complex, and suggested interactions with expression-repressing RNA-binding proteins $(\mathrm{ZC} 3 \mathrm{H} 8, \mathrm{ZC} 3 \mathrm{H} 30$, and $\mathrm{ZC} 3 \mathrm{H} 46)$ and the deadenylase PARN3.

Keywords

Trypanosoma, mRNA decay, mRNA degradation, Crr4/Caf1/Not

\section{Open Peer Review}

\begin{tabular}{|c|c|c|}
\hline & 1 & 2 \\
\hline version 1 & $?$ & $?$ \\
\hline 09 Jun 2017 & view & view \\
\hline
\end{tabular}

1. Susanne Kramer, University of Würzburg, Würzburg, Germany

2. Martine A. Collart ID, University of Geneva, Geneva, Switzerland Any reports and responses or comments on the article can be found at the end of the article. 
This article is included in the Sidra Medicine

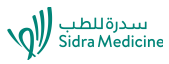

gateway.

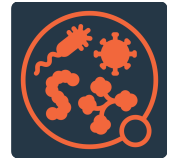

This article is included in the Pathogens

gateway.

\section{Corresponding author: Christine Clayton (cclayton@zmbh.uni-heidelberg.de)}

Author roles: Chakraborty C: Funding Acquisition, Supervision, Writing - Original Draft Preparation, Writing - Review \& Editing; Fadda A: Investigation, Methodology, Writing - Original Draft Preparation, Writing - Review \& Editing; Erben E: Data Curation, Formal Analysis, Methodology, Software, Writing - Review \& Editing; Lueong S: Methodology, Supervision; Hoheisel J: Investigation, Methodology; Mugo E: Methodology, Supervision; Clayton C: Investigation, Supervision

Competing interests: No competing interests were disclosed.

Grant information: This work was funded by core funding to CC, and by the Deutsche Forschungsgemeinschaft (grant Cl112/24).

The funders had no role in study design, data collection and analysis, decision to publish, or preparation of the manuscript.

Copyright: $\odot 2017$ Chakraborty C et al. This is an open access article distributed under the terms of the Creative Commons Attribution License, which permits unrestricted use, distribution, and reproduction in any medium, provided the original work is properly cited. Data associated with the article are available under the terms of the Creative Commons Zero "No rights reserved" data waiver (CC0 1.0 Public domain dedication).

How to cite this article: Chakraborty C, Fadda A, Erben E et al. Interactions of CAF1-NOT complex components from Trypanosoma brucei [version 1; peer review: 2 approved with reservations] F1000Research 2017, 6:858

https://doi.org/10.12688/f1000research.11750.1

First published: 09 Jun 2017, 6:858 https://doi.org/10.12688/f1000research.11750.1 


\section{Introduction}

The CCR4/CAF1-NOT complex (NOT complex) represses translation and deadenylates polyadenylated mRNAs, thus priming them for degradation. It has been found in all eukaryotes examined so far. CCR4 and CAF1 are deadenylases; NOT1 is a large protein upon which the whole complex is assembled, and it binds directly to most other components. NOT3 or NOT5 (two proteins in yeast), NOT2 and CAF40 assemble on one side of the complex, while CAF1, CCR4, NOT10, and NOT11 are on the other. ${ }^{1,2}$. Another component, called Not4p in yeast, is less evolutionarily conserved; it participates in protein quality control by acting as an E3 ligase ${ }^{3}$. Artificial attachment of any of the complex components to a reporter mRNA represses expression, presumably via recruitment of the whole complex ${ }^{4}$. Analysis of unstable mRNAs in animal cells has revealed that in many cases, destabilizing elements in the 3'-untranslated region are recognized by specific RNA-binding proteins (RBPs), which in turn recruit components of the NOT complex via binding to different subunits ${ }^{5-8}$.

The unicellular eukaryote Trypanosoma brucei belongs to the family Kinetoplastidae, which also includes Leishmania and Trypanosoma cruzi. All of these parasites cause serious disease in humans and other mammals, and all share the same unusual mode of gene expression, with polycistronic transcription and mRNA trans splicing. Since individual mRNAs are co-transcribed, control of gene expression is almost exclusively post-transcriptional. There are three types of deadenylation machineries: PAN $2 / 3^{9}$ PARN proteins ${ }^{10}$ and the CAF1-NOT complex ${ }^{11-13}$. The trypanosome CAF1-NOT complex, which is most important in deadenylation, consists of CAF1 (the only deadenylase ${ }^{12}$ ), NOT1 (Tb927.10.1510), NOT2 (Tb927.6.850), NOT3/5 (Tb927.3.1920), NOT9/CAF40 (Tb927.4.410), NOT10 (Tb927.10.8720), NOT11 (Tb927.8.1960), and the multi-purpose helicase DHH1 (Tb927.10.3990) $)^{11-13}$. Pairwise yeast-two-hybrid results indicated that trypanosome CAF1 interacted with NOT10 and the N-terminal half of NOT1, and NOT10 interacted with NOT $3 / 5^{13}$; depletion of NOT10 led to detachment of CAF1 from the NOT complex ${ }^{13}$. Later, yeast 2-hybrid screens using a "mini-library" of fulllength proteins implicated in mRNA metabolism confirmed the expected interactions of NOT1 with NOT2 and CAF1, but also suggested that CAF1 interacts with four proteins with RNA-binding domains: RBP31, DRBD5, ZC3H5, and ZC3H15. Interactions of NOT1 with two proteins of unknown function - Tb927.4.3330 and Tb927.11.2030 - were also found ${ }^{14}$. In this paper we have investigated the interactions of NOT2, NOT10, NOT11 and NOT9/CAF40.

\section{Results}

\section{Yeast two-hybrid screens}

Our trypanosome yeast two-hybrid prey library was made by random shotgun genomic cloning. The library has several million independent yeast clones, each of which expresses a different protein fragment (with roughly $1 / 12$ being within an open reading frame and in-frame) ${ }^{15}$. NOT2, NOT10, NOT11 and CAF40 were used as baits to screen the library by mating. We also included another protein of interest, CFB1. CFB1 is expressed in bloodstream-form trypanosomes. Its function is somewhat enigmatic, though it is probably required for optimal cell growth ${ }^{16}$. All results are in Table S1. For the NOT complex components, at least one million diploid progeny were subjected to selection, resulting in between 100 and 800 surviving colonies, from which inserts were amplified and subjected to high-throughput sequencing. To find interacting proteins, we selected open reading frames for which there were at least two different in-frame sequences represented by at least 20 reads (Table $\mathrm{S} 1$, sheet 2). This procedure gives false positives and false negatives. Poor folding could result in a false positive due to aberrant exposure of hydrophobic surfaces, or in a false negative due to incorrect formation of a folding-dependent interaction domain. In addition, proteins for which the whole protein, or a (near-) complete $\mathrm{N}$-terminus, are required for interaction would be excluded.

We obtained 6, 158, 15 and 3 interaction partners for NOT2, NOT10, NOT11 and CAF40 respectively; CFB1 interacted promiscuously with over 800 partners. (These did not include the only validated partner, MKT1, but we had previously found that MKT1 seems only to interact as a complete protein ${ }^{15}$.) To judge the likely specificity of the interactions, we compared them with those of MKT1 ${ }^{15}$, RBP10 (Mugo and Clayton; unpublished study, manuscript submitted), 4EIP and Tb927.7.2780 (unpublished studies; Terrao, ZMBH). The result for NOT10 strongly suggested a tendency for non-specific interactions, although not as severe as for CFB1. The most specific interactions for NOT2, NOT10 and NOT11 are shown in Table 1 . It was notable that no interactions with either CAF1 or NOT1 were detected; this might be because the fragments encoded in our prey library are too small. NOT11 had two unique interactions, with a DNAj domain protein (Tb927.9.1560) and mitochondrial EF-Tu; the latter is unlikely to be physiological because of the protein location. There were also two interactors that were shared only with the promiscuous CFB1 - a protein phosphatase and a protein of unknown function, both of which are probably in the cytoplasm. NOT11 interacted with itself, and shared 7 other interactions with NOT10. Some of these, such as the interaction between NOT10 and NOT11, are likely to be genuine - NOT10 interacts with NOT11 in yeasts,17. Apart from NOT11, none of these proteins interacts with bloodstream-form trypanosome $\mathrm{mRNA}^{14}$ or has any effect in the tethering assay ${ }^{14,18}$.

To supplement results from the random fragment library, we used recombinant CAF40 to screen a cDNA protein expression array and a similar array displaying proteins from full-length open reading frames of proteins involved in mRNA metabolism ${ }^{14,19}$. Two other proteins, Aurora kinase B and T. brucei polo-like kinase, were included as bait controls to exclude "sticky" proteins. Using the open reading frame array, no specific interaction partners were found. For the cDNA array, selected clones were sequenced, then checked in a pairwise yeast-two hybrid assay. The only confirmed interaction was with the nascent polypeptide associated complex alpha subunit-like protein (Tb927.9.8100/8130). An interaction between the yeast NOT complex and the nascent polypeptide associated complex was previously reported in yeast; the beta subunit Egd1p, had a weak two-hybrid interaction with Caf40p, but much stronger interactions were detected between Egdlp and some other NOT complex components ${ }^{20}$. The significance of the possible interaction is unclear since the nascent polypeptide associated complex was not found in the affinity 
Table 1. Most specific interaction partners of NOT2, NOT11 and CAF40. For details see Table S1. Only proteins that interacted in less than four screens are shown; none were positive with MKT1 or 4EIP. The columns for NOT2, NOT10, NOT11 and CAF40 show the number of different interacting protein fragments. The 4EIP, 7.2780 and CFB1 screens were done at different times, with different sequencing depth, so that the numbers are not strictly comparable. These are therefore designated "y" for "yes" and "0" for less than 2 interacting fragments. "Loc" indicates the subcellular location, when known, either from the TrypTag project (http://tryptag.org) or from other information. "cyt" = cytosol, "mit" = mitochondrion", "nuc" = nucleolus. POMP37 was a mitochondrial membrane protein by proteomics but the GFP-tagged protein in TrypTag has an ER-type pattern.

\begin{tabular}{|l|l|l|l|l|l|l|l|l|l|}
\hline Tb927 & FOT2 & NOT10 & NOT11 & CAF40 & 4EIP & 7.2780 & CFB1 & Loc \\
\hline 7.7210 & POMP37 & 2 & 12 & 0 & 0 & 0 & $y$ & 0 & $?$ \\
\hline 8.7960 & unknown & 0 & 0 & 2 & $y$ & 0 & 0 & \\
\hline 11.16280 & Ribosomal protein L2 L8 & 2 & 0 & 0 & 0 & $y$ & 0 & 0 & nuc, cyt \\
\hline 11.13310 & spectrin repeat protein & 2 & 0 & 0 & 0 & $y$ & 0 & 0 & nuc \\
\hline $\mathbf{8 . 1 9 6 0}$ & NOT11 & 0 & 10 & 2 & 0 & 0 & $y$ & 0 & \\
\hline 7.2070 & DNAJ & 0 & 2 & 6 & 0 & 0 & 0 & 0 & \\
\hline 9.10370 & TAX-1, flagellar protein & 0 & 4 & 5 & 0 & 0 & 0 & 0 & cyt \\
\hline 11.7040 & pterin enzyme & 0 & 2 & 4 & 0 & 0 & 0 & 0 & \\
\hline 5.2440 & WW domain & 0 & 19 & 2 & 0 & 0 & 0 & 0 & \\
\hline 6.860 & unknown & 0 & 14 & 4 & 0 & 0 & 0 & 0 & \\
\hline 1.3290 & unknown & 0 & 7 & 2 & 0 & 0 & 0 & y & \\
\hline 9.1560 & DNAj domain & 0 & 0 & 2 & 0 & 0 & 0 & 0 & \\
\hline 10.13360 & Mitochondrial EF-Tu & 0 & 0 & 2 & 0 & 0 & 0 & 0 & mit \\
\hline 10.4930 & protein phosphatase & 0 & 0 & 2 & 0 & 0 & 0 & $y$ & cyt \\
\hline 3.1880 & unknown & 0 & 0 & 2 & 0 & 0 & 0 & y & cyt \\
\hline
\end{tabular}

purification (see below).

Proteins that co-purify with V5-tagged CAF40

To find proteins that co-purify with CAF40, we integrated a sequence encoding a V5 tag in frame with the 5' end of the open reading frame in the genome of bloodstream form trypanosomes ${ }^{21}$. The resulting parasites are expected to express N-terminally V5tagged CAF40 at an approximately normal level. Eluates from two independent pull-downs - one with RNase inhibitor, and the other with RNase - were analysed by mass spectrometry, in parallel with a single control from wild-type cells (no tag) (Table S2, sheet 1). As additional controls we used the results from three other tandem affinity purifications of tagged GFP. To detect proteins that are frequent contaminants after affinity purification we compared the results with those from many other experiments from our and other labs. Since our CAF40 experiment included only two replicates, all of the results need further confirmation before definitive conclusions can be drawn. Nevertheless, V5-tagged CAF40 showed specific, reproducible RNA-independent pull down of the NOT1, NOT10, NOT11 and CAF1 subunits of the CAF1-NOT complex (Table S2, sheet 2), while co-purification of NOT2 and NOT5 was diminished by RNAse treatment (Table S2, sheet 3). The results also suggested RNA-independent association with three potential RNA-binding proteins, ZC3H8, ZC3H30 and ZC3H46. Interestingly, all three of these RNA-binding proteins were found associated with mRNA $^{14}$ and each one repressed expression in tethering screens ${ }^{14,18}$. We therefore speculate that they may repress expression by recruiting the NOT complex via CAF40. Some of the proteins that were pulled down in the absence of RNase also appeared interesting; they included 7 known or potential RNAbinding proteins (CSBII, DRBD4 (PTB2), PUF6, ZC3H28 and ZC3H41, HNRNPH and Tb927.11.14090), and the 5'-3' exoribonuclease XRNA (at rather low coverage). This was, however, only a single experiment, so the results will not be discussed further.

Dataset 1. Table S1: Yeast 2-hybrid results. A detailed legend is on the first sheet

http://dx.doi.org/10.5256/f1000research.11750.d163337

Dataset 2. Table S2: Mass spectrometry of tandem affinity purified CAF40. A detailed legend is on the first sheet

http://dx.doi.org/10.5256/f1000research.11750.d163338

\section{Conclusions}

The yeast 2-hybrid data by themselves provided no clues concerning functional partners of the NOT complex components investigated, beyond confirming the likely interaction between NOT11 and NOT10. Nevertheless, they may be useful in 
conjunction with other results; for example, the protein phosphatase Tb927.10.4930 might be implicated in regulation. Our mass spectrometry of CAF40, in contrast, did point to some proteins that might be involved in recruiting the NOT complex to mRNAs; this is especially likely for those proteins that also repressed expression in the tethering assay. We therefore hope that the results will be useful to others who may wish to investigate the modes of action of these proteins in detail.

\section{Methods}

Yeast two-hybrid analysis

The Matchmaker GAL4 Two-Hybrid System3 (Clontech) was used, with Gateway cloning of amplified open reading frames to create bait plasmids. The trypanosome prey library, sequencing methods and bioinformatic analysis have been previously described ${ }^{15}$. Briefly, bait plasmids were transformed into AH109 yeast, and the pool of prey plasmids were transformed into the Y187 strains. The cells were allowed to mate, plated on SD agar plates lacking tryptophan, leucine, or both (double drop-out medium) to calculate mating efficiency, then plated without tryptophan, leucine, adenine and histidine (quadruple drop-out medium), and incubated for 3 to 5 days at $30^{\circ} \mathrm{C}$. The resulting colonies were re-plated on quadruple drop-out $\mathrm{SD}$ plates with $40 \mu \mathrm{g} / \mathrm{ml}$ $\mathrm{X}-\alpha$-Gal and 3-amino triazole (3-AT, 0.5 to $2 \mathrm{mM}$ ), and incubated for 3 to 5 days. Blue colonies were then pooled and grown overnight in quadruple drop-out medium with 3-amino triazole for plasmid isolation. The plasmid inserts were amplified with barcoded primers, pooled and sent for library preparation by David Ibbersson (BioQuant, Heidelberg, Germany), then sequenced (Illumina Hi-Seq, EMBL, Heidelberg., Germany). The numbers of reads obtained are in Table $\mathrm{S} 1$, Sheet 1.

Reads were aligned to the T. brucei 927 genome, as described ${ }^{15}$. We selected sequences that were present at least 10 times, and that had annotated open reading frames that were in frame with the DNA-binding domain (Table S1, sheets 3-5). We then chose a list of unique open reading frames with only one copy each of repeated genes ${ }^{22}$. We also restricted the selection to open reading frames that included no more than 13 codons upstream of the start codon, and included at least 6 codons before the stop codon. Individual results are in Table S1, sheets 4-7 and final results are summarized in Table S1, sheet 2. Sheet 3 includes locations found in screens with more than three different baits.

Affinity purification of V5-CAF40 and mass spectrometry About $10^{10}$ bloodstream form cultured bloodstream-form $T$ brucei carrying endogenously V5-tagged CAF40 were subjected to immunoprecipitation, as previously described ${ }^{13}$. The eluate was run $1 \mathrm{~cm}$ in $10 \%$ SDS PAGE gel, and was cut in 6 pieces for MassSpectrometry analysis. The piece were transferred to a 96-well plate and reduced, alkylated and digested with trypsin, as described ${ }^{23}$, except that triethylammoniumbicarbonate buffer was used instead of ammoniumbicarbonate buffer. Following digestion, tryptic peptides were extracted from the gel pieces with $50 \%$ acetonitrile $/ 0.1 \%$ TFA, and concentrated nearly to dryness in a speedVac vacuum centrifuge. Peptides were separated on an analytical column (75um $\times 150 \mathrm{~mm}$ ) with a flow rate of $300 \mathrm{nl} / \mathrm{min}$ (nanoAcquity, Waters) using $1 \%$ formic acid and an acetonitrile gradient increasing from $3 \%$ acetonitrile to $37 \%$ acetonitrile over 50 minutes. The UPLC system was on-line coupled to an ESI LTQ Orbitrap XL MS (Thermo Fisher). One survey scan (res: 60000) was followed by 5 information dependent product ion scans in the LTQ. Only doubly and triply charged ions were selected for fragmentation.

Data were analyzed using Proteome Discoverer 1.4 and Mascot (Matrix Science; version 2.4). Mascot was set up to search the the TriTrypDB_9.0_Tbrucei_2015Jan database (20400 entries) using trypsin as protease, a fragment ion mass tolerance of 0.50 $\mathrm{Da}$ and a parent mass tolerance of $100 \mathrm{ppm}$. Iodoacetamide derivative of cysteine was specified in Mascot as a fixed modification. Deamidation of asparagine and glutamic acid, as well as oxidation of methionine, were specified in Mascot as variable modifications. Target decoy PSM validator was set to a target FDR (strict) of 0.01. Results are in Table S2.

\section{Data availability}

Dataset 1: Table S1: Yeast 2-hybrid results. A detailed legend is on the first sheet. doi, 10.5256/f1000research.11750.d163337

Dataset 2: Table S2: Mass spectrometry of tandem affinity purified CAF40. A detailed legend is on the first sheet. doi, 10.5256/f1000research.11750.d163338

\section{Competing interests}

No competing interests were disclosed.

\section{Grant information}

This work was funded by core funding to $\mathrm{CC}$, and by the Deutsche Forschungsgemeinschaft (grant Cl112/24).

The funders had no role in study design, data collection and analysis, decision to publish, or preparation of the manuscript.

\section{Acknowledgements}

We thank David Ibbersson (BioQuant, Heidelberg) for library construction and sequencing. The pairwise interaction between CAF40 and the nascent polypeptide associated complex alpha subunit was tested in the DKFZ two-hybrid facility.
1. Villanyi Z, Collart MA: Building on the Ccr4-Not architecture. Bioessays. 2016; 38(10): 997-1002.

PubMed Abstract | Publisher Full Text | Free Full Text
2. Ukleja M, Cuellar J, Siwaszek A, et al.: The architecture of the Schizosaccharomyces pombe CCR4-NOT complex. Nat Commun. 2016; 7: 10433. PubMed Abstract | Publisher Full Text | Free Full Text 
3. Collart MA, Panasenko OO: The Ccr4-not complex. Gene. 2012; 492(1): 42-53. PubMed Abstract | Publisher Full Text

4. Bawankar P, Loh B, Wohlbold L, et al:: NOT10 and C2orf29/NOT11 form a conserved module of the CCR4-NOT complex that docks onto the NOT1 $\mathrm{N}$-terminal domain. RNA Biol. 2013; 10(2): 228-44. PubMed Abstract | Publisher Full Text | Free Full Text

5. Sgromo A, Raisch T, Bawankar $\mathrm{P}$, et al:: A CAF40-binding motif facilitates recruitment of the CCR4-NOT complex to mRNAs targeted by Drosophila Roquin. Nat Commun. 2017; 8: 14307.

PubMed Abstract | Publisher Full Text | Free Full Text

6. Suzuki A, Saba R, Miyoshi K, et al:: Interaction between NANOS2 and the CCR4NOT deadenylation complex is essential for male germ cell development in mouse. PLoS One. 2012; 7(3): e33558.

PubMed Abstract | Publisher Full Text | Free Full Text

7. Sandler H, Kreth J, Timmers HT, et al:: Not1 mediates recruitment of the deadenylase Caf1 to mRNAs targeted for degradation by tristetraprolin. Nucleic Acids Res. 2011; 39(10): 4373-86.

PubMed Abstract | Publisher Full Text | Free Full Text

8. Van Etten J, Schagat TL, Hrit J, et al:: Human Pumilio proteins recruit multiple deadenylases to efficiently repress messenger RNAs. J Biol Chem. 2012; 287(43): 36370-83.

PubMed Abstract | Publisher Full Text | Free Full Text

9. Schwede A, Manful T, Jha BA, et al.: The role of deadenylation in the degradation of unstable mRNAs in trypanosomes. Nucleic Acids Res. 2009; 37(6): 5511-28. PubMed Abstract | Publisher Full Text | Free Full Text

10. Utter CJ, Garcia SA, Milone J, et al:: PolyA-specific ribonuclease (PARN-1) function in stage-specific mRNA turnover in Trypanosoma brucei. Eukaryot Cell. 2011; 10(9): 1230-40.

PubMed Abstract | Publisher Full Text | Free Full Text

11. Erben E, Chakraborty C, Clayton C: The CAF1-NOT complex of trypanosomes. Front Genet. 2014; 4: 299

PubMed Abstract | Publisher Full Text | Free Full Text

12. Schwede $A$, Ellis $L$, Luther $\mathrm{J}$, et al: : A role for Caf1 in mRNA deadenylation and decay in trypanosomes and human cells. Nucleic Acids Res. 2008; 36(10): 3374-88. PubMed Abstract | Publisher Full Text | Free Full Text

13. Färber V, Erben E, Sharma S, et al:: Trypanosome CNOT10 is essential for the integrity of the NOT deadenylase complex and for degradation of many mRNAs. Nucleic Acids Res. 2013; 41(2): 1211-22. PubMed Abstract | Publisher Full Text | Free Full Text

14. Lueong S, Merce C, Fischer B, et al:: Gene expression regulatory networks in Trypanosoma brucei: insights into the role of the mRNA-binding proteome.
Mol Microbiol. 2016; 100(3): 457-71.

PubMed Abstract | Publisher Full Text

15. Singh A, Minia I, Droll D, et al: Trypanosome MKT1 and the RNA-binding protein ZC3H11: interactions and potential roles in post-transcriptional regulatory networks. Nucleic Acids Res. 2014; 42(7): 4652-68.

PubMed Abstract | Publisher Full Text | Free Full Text

16. Benz C, Clayton CE: The F-box protein CFB2 is required for cytokinesis of bloodstream-form Trypanosoma brucei. Mol Biochem Parasitol. 2007; 156(2): 217-24.

PubMed Abstract | Publisher Full Text

17. Mauxion F, Prève $B$, Séraphin B: C2ORF29/CNOT11 and CNOT10 form a new module of the CCR4-NOT complex. RNA Biol. 2013; 10(2): 267-76. PubMed Abstract | Publisher Full Text | Free Full Text

18. Erben ED, Fadda A, Lueong $\mathrm{S}$, et al:: A genome-wide tethering screen reveals novel potential post-transcriptional regulators in Trypanosoma brucei. PLOS Pathog. 2014; 10(6): e1004178. PubMed Abstract | Publisher Full Text | Free Full Text

19. Hoheisel JD, Alhamdani MS, Schröder C: Affinity-based microarrays for proteomic analysis of cancer tissues. Proteomics Clin Appl. 2013; 7(1-2): 8-15. PubMed Abstract | Publisher Full Text

20. Panasenko O, Landrieux E, Feuermann M, et al.: The yeast Ccr4-Not complex controls ubiquitination of the nascent-associated polypeptide (NAC-EGD) complex. J Biol Chem. 2006; 281(42): 31389-98.

PubMed Abstract | Publisher Full Text

21. Shen S, Arhin GK, Ullu E, et al.: In vivo epitope tagging of Trypanosoma brucei genes using a one step PCR-based strategy. Mol Biochem Parasitol. 2001; 113(1): 171-3.

PubMed Abstract | Publisher Full Text

22. Siegel TN, Hekstra DR, Wang X, et al:: Genome-wide analysis of mRNA abundance in two life-cycle stages of Trypanosoma brucei and identification of splicing and polyadenylation sites. Nucleic Acids Res. 2010; 38(15): 4946-57. PubMed Abstract | Publisher Full Text | Free Full Text

23. Tegha-Dunghu J, Neumann B, Reber S, et al.: EML3 is a nuclear microtubulebinding protein required for the correct alignment of chromosomes in metaphase. J Cell Sci. 2008; 121(Pt 10): 1718-26. PubMed Abstract | Publisher Full Text

24. Chakraborty C, Fadda A, Erben E, et al:: Dataset 1 in: Interactions of CAF1-NOT complex components from Trypanosoma brucei. F1000Research. 2017. Data Source

25. Chakraborty C, Fadda A, Erben E, et al.: Dataset 2 in: Interactions of CAF1-NOT complex components from Trypanosoma brucei. F1000Research. 2017. Data Source 


\title{
Open Peer Review
}

\section{Current Peer Review Status: ? ?}

\section{Version 1}

Reviewer Report 20 June 2017

https://doi.org/10.5256/f1000research.12692.r23381

(C) 2017 Collart M. This is an open access peer review report distributed under the terms of the Creative Commons Attribution License, which permits unrestricted use, distribution, and reproduction in any medium, provided the original work is properly cited.

\author{
Martine A. Collart \\ Department of Microbiology and Molecular Medicine, Faculty of Medicine, University of Geneva, \\ Geneva, Switzerland
}

In this study the authors try to identify proteins interacting with specific components of the CAF1NOT complex in Trypanosome brucei. They used the 2 hybrid method for this and analyzed CBF1 as a control bait to determine specificity. Since they did not identify any significant partner for one of their baits, CAF40, they used alternative approaches, one of which, the affinity purification of CAF40 from Trypanosome brucei followed by mass spectrometry, gave some results.

\section{$\underline{\text { General comments }}$}

This work really does not go beyond the description of the screening and identified potential partners with a very minimal description of these potential partners.

The filtering used to identify which clones are more likely to be true interaction partners has its limitations. The authors use a protein of interest CBF1, find 800 partners and conclude that Cbf1 is promiscuous. We have no information about this protein, or why the identification of 800 partners means that it is promiscuous. It is also not clear why comparing partners of the CAF1-NOT proteins to those of CBF1 is useful, and the authors end up using data that is not in this manuscript, namely partners of others proteins that were screened, to determine which proteins might be specific partners of the CAF1-NOT proteins. It seems that in this case, it would just be more appropriate to provide all the clones isolated for the specific baits and then use a letter in the table to indicate that clones were isolated also in many other unrelated screens. The data exists in a supplementary table, but it could be put in a reader-friendly manner like Table 1 in the main text.

It is curious that no CAF1-NOT components were isolated. I am not sure that the size of the library fragments is a good explanation. This could be tested directly, by using the structural information available and make a very small NOT1 clone. But in any event, it seems that the more likely explanation is that the screening was not saturated. 
Previous data has indicated that chaperones co-purify with NOT10-11, hence the finding of many partners may not be indicative of non-specific interactions but may have significance.

In conclusion, I do think that the results of a screen like this would be useful to the community. It could be that if we wait for the authors to try to follow up on all the clones and get relevant biological data, this may take a lot of time and hence some of the data will end up not being made visible. However I feel that the effort the authors make to validate some clones over others is not a good idea. In any event, if they chose to do so, then there should be more description about these clones.

\section{Minor comment}

The way by which Not4 acts in protein quality control is somewhat controversial, I would not write that it is by acting as an E3 ligase.

Is the work clearly and accurately presented and does it cite the current literature? Partly

Is the study design appropriate and is the work technically sound?

Yes

Are sufficient details of methods and analysis provided to allow replication by others? Yes

If applicable, is the statistical analysis and its interpretation appropriate? Partly

Are all the source data underlying the results available to ensure full reproducibility? Yes

Are the conclusions drawn adequately supported by the results? Yes

Competing Interests: No competing interests were disclosed.

I confirm that I have read this submission and believe that I have an appropriate level of expertise to confirm that it is of an acceptable scientific standard, however I have significant reservations, as outlined above.

Author Response ( F1000Research Advisory Board Member ) 20 Jun 2017

Christine Clayton, Deutsche Krebsforschungszentrum, Heidelberg, Germany

We agree entirely with both reviewers that these results need more follow-up in order to be really useful. For the yeast 2 -hybrid, this would require individual verification by 2 -hybrid on full-length proteins, followed by immunoprecipitations. The CAF40 mass spectrometry 
would need to be repeated twice more, then individual partners followed up by other means. We had obviously hoped that some CAF40 interaction partners would emerge from both screens, but that did not happen.

We decided to publish as is because my lab does not currently have the resources available for further follow-up and it seemed silly to just leave the data on a private hard disk. We thought that at least, it could help other researchers who are doing pull-downs or twohybrid. First, it will prevent other people from wasting time doing the 2-hybrid screens again. Secondly, it might help other people to decide which results to follow up in their own interaction experiments. For example, if a lab is working on a protein $X$, and discovers that it pulls down a NOT complex subunit, they could look at our results and see if their protein $X$ was in one of our datasets. If it was, that would encourage them to investigate further.

Competing Interests: No competing interests were disclosed.

Reviewer Report 13 June 2017

https://doi.org/10.5256/f1000research.12692.r23380

(C) 2017 Kramer S. This is an open access peer review report distributed under the terms of the Creative Commons Attribution License, which permits unrestricted use, distribution, and reproduction in any medium, provided the original work is properly cited.

\section{Susanne Kramer}

Department of Cell and Developmental Biology, Biocenter, University of Würzburg, Würzburg, Germany

The authors were interested in identifying additional subunits of the trypanosome CAF1-NOT complex, an important macromolecular assembly involved in the first step (deadenylation) of mRNA degradation. Towards this aim, they carried out a genome-wide $\mathrm{Y} 2 \mathrm{H}$ screen with a shotgun library using four known subunits of the complex as baits. For one of these bait proteins (CAF40), interactions were also determined by Co-IPs. While the question is of great interest, my main problem is that the experiments do not actually identify any new members of the CAF-NOT complex with confidence, contrary to what is suggested by the title.

The problem with the $\mathrm{Y} 2 \mathrm{H}$ screen is a lack of adequate controls. With one exception, none of the previously-known interacting proteins were identified (lack of positive controls). The negative control, $\mathrm{Y} 2 \mathrm{H}$ with CBP1, yielded over eight hundred interaction partners, but not the one that was previously known; the authors state themselves that this clearly lacks specificity. None of the identified proteins from the $\mathrm{Y} 2 \mathrm{H}$ screen were verified, for example by reciprocal IP, or by localisation studies (members of the CAF1-NOT complex are expected in P-bodies; thus, a P-body localisation seen in TrypTag(!), could indicate, although not prove, a correct hit). I was also confused with the presentation of the data on several occasions. For example, on page 3 it says 'we obtained 6, 158, 15 and 3 interaction partners with NOT2, NOT10, NOT11 and CAF40 ...', but I could not find a list of these proteins anywhere. The numbers in the abstract and in Table 1 are 
different. I understand that these were the most specific interaction partners, but I was confused a mitochondrial protein was among those. Overall, I felt that the presentation of the data in the tables was a little 'raw'. In their conclusion, the authors state that 'The $\mathrm{Y} 2 \mathrm{H}$ data by themselves provided no clues confirming functional partners of the Not complex'.

The affinity purification of Caf40 \pm RNAse identified several interesting proteins, although the one CAF40 interaction partner identified in the $\mathrm{Y} 2 \mathrm{H}$ was not among these. However, these results were weakened by the authors themselves as the paragraph ends with 'This was, however, only a single experiment, so the results will not be discussed further'. As with the $\mathrm{Y} 2 \mathrm{H}$ data, I also felt that the data presentation was rather raw.

I'm sorry not to be more positive with this manuscript. I do realise that the $\mathrm{Y} 2 \mathrm{H}$ was a lot of work, but it is nonetheless important to increase confidence in the results using the controls/replicates suggested above. An additional approach such as BioID would also be a good control, although I realise that this is beyond the scope of this manuscript.

Is the work clearly and accurately presented and does it cite the current literature? Partly

Is the study design appropriate and is the work technically sound?

No

Are sufficient details of methods and analysis provided to allow replication by others? Yes

If applicable, is the statistical analysis and its interpretation appropriate? Not applicable

Are all the source data underlying the results available to ensure full reproducibility? Yes

Are the conclusions drawn adequately supported by the results? Yes

Competing Interests: No competing interests were disclosed.

I confirm that I have read this submission and believe that I have an appropriate level of expertise to confirm that it is of an acceptable scientific standard, however I have significant reservations, as outlined above. 
The benefits of publishing with F1000Research:

- Your article is published within days, with no editorial bias

- You can publish traditional articles, null/negative results, case reports, data notes and more

- The peer review process is transparent and collaborative

- Your article is indexed in PubMed after passing peer review

- Dedicated customer support at every stage

For pre-submission enquiries, contact research@f1000.com 